\title{
The Effect of Model Based Health Education on Performing Breast Self- Examination in Women
}

\author{
Hossein Ashtarian $^{1}$, Mehdi Khezeli $^{2}$, Shahram Saeidi $^{2}$, Alireza Zangeneh $^{2}$ \\ 1Department of Heal Education, School of Public Health, Kermanshah University of Medical Sciences, Kermanshah, Iran \\ ${ }^{2}$ Social Development and Health Promotion Research Center, Health Institute, Kermanshah University of Medical Sciences, Kermanshah, Iran \\ Address for Correspondence: Mehdi Khezeli, E-mail: khezelimehdi@yahoo.com \\ Received: 08.06.2019; Accepted: 14.10.2019; Available Online Date: 27.01.2020 \\ (OCopyright 2019 by Dokuz Eylül University, Institute of Health Sciences - Available online at www.jbachs.org
}

Cite this article as: Ashtarian H, Khezeli M, Saeidi S, Zangeneh A. The Effect of Model Based Health Education on Performing Breast Self-Examination in Women. J Basic Clin Health Sci 2020; 1:15-21.

\begin{abstract}
Purpose: The aim of this study was to determine the effect of integrated model based education on performing Breast Self-examination in women.

Methods: This interventional study was conducted with the participation of 140 women in two intervention and control groups in 2016. Intervention program implemented based on Stages of Change and Health Belief Model (HBM). The data were analyzed using SPSS version 19.

Results: Mean age of women was $32.86 \pm 6.1$ years. The stages of change in the intervention group moved toward the active stages; from $28.6 \%$ to $56.1 \%(p<.001)$. After the intervention, susceptibility $(16.98 \pm 3.66$ vs. $13.44 \pm 4.01)$, severity $(23.93 \pm 4.18$ vs. $20.25 \pm 5.09)$, benefits $(27.42 \pm 3.05$ vs. $25.19 \pm 3.43)$, self-efficacy $(22.67 \pm 4.66$ vs. $19.42 \pm 5.58)$, and accuracy of breast self-examination $(59.84 \pm 21.09 \mathrm{vs}$. $38.30 \pm 27.88)$ in the educational group was significantly higher than the control group $(p<0.05)$.
\end{abstract}

Conclusion: Intervention based on health belief model in combination with stages of change model, promoted the beliefs related to breast cancer and also performing breast self-examination.

Keywords: Breast Self-examination, Health Belief Model, Self-efficacy, Stages of Change Model

\section{INTRODUCTION}

Worldwide, breast cancer is most prevalent cancer in women however its 5-year survival rate is over $89 \%$ if detected early (1). Breast cancer also is the most common cancer in Iranian women and has increased during recent years in Iran. The age standardized rate of breast cancer in Iran has been reported 33.21 per 100,000 (2). It also is ranked as the second-leading cause of death from female cancers in Iranian women (3). Since the there is no definitive treatment for this cancer, and treatment is a multiple and complex procedure including breast conserving surgery, mastectomy, radiation therapy, and chemotherapy therefore early detection methods are very important for secondary prevention $(1,4)$. Breast self-examination is a useful method to early detection of breast cancer because it is a simple, costless, noninvasive method that can be practiced by the individual without a need to technical equipment, and with no side effects (5). According to the results of a study that compared the detection methods for breast cancer include breast self-examination (BSE), MRI and clinical breast examination (CBE), of the 14 diagnosed cancers, six cases was detected by BSE, six cases by MRI and two cases through $\mathrm{CBE}$ respectively (6).
Despite the relative benefits, it was shown that BSE was made irregularly or never made in the studies conducted on women of all age group (7). Various studies have reported different statistics of BSE in Iranian women, including $51 \%$ in Dezful (4), $46 \%$ in Mazandaran (8), 26\% in Hamadan (9), 12.7\% in Kerman (10), and $11.8 \%$ in Tehran (11). Also a previous study in Gilan-e gharb city - the setting of the present study- showed that Less than $30 \%$ of women in the general population have done BSE regularly (12).

Performing BSE is dependent on health beliefs of people about breast health beside the level of knowledge, socio-demographic characteristics and experiences (13). Health Belief Model (HBM) is one of the most appropriate models of health education and health promotion which is widely used in the study on breast examination (14). According to HBM, if a woman understands that she is susceptible to breast cancer and this cancer is a serious disease, believe that preventive action has positive results, the barriers of that behavior is less than its acquired benefits and believe to doing health behavior (self-efficiency), it is more likely to do that behavior (15). One of the models that can be used to study breast self-examination 
behavior along with the Health Belief Model is the Stages of Change Model (SOC) which suggest the behavior change occurs in a fivestep including- 1) Precontemplation stage: Women don't think about $B S E, 2)$ Contemplation stage: in which women do not perform BSE, but they are thinking about doing it during the next six months, 3) Preparation stage: women do not perform but they are ready to do it in the next 30 days, 4) Action stage: women doing BSE for less than six months, and 5) Maintenance stage: woman did BSE more than 6 months (12). SOC model emphasized that people are not similar in adopting a behavior. Also SOC proposed that changing or adopting healthy behavior occurs during different stages (16). Considering the importance and valuable role of breast self-examination in diagnosis of breast masses, and given that the rates of BSE is lower than the expected rate educational opportunities in health care centers, this study was conducted to examined the hypothesis that educational intervention based on the Health Belief Model had a positive effect on the stages of change and accuracy of breast self-examination in women of Gilan-e Gharb city.

\section{METHODS}

Participants and sampling: This is an interventional study. In this study random selection of subjects and the having control group were met. Sample size was determined using results of the study by Ashtarian and colleagues (12), according to which the mean and standard deviation of Perceived Barriers- one construct of HBM - in two group was $12.58 \pm 3.44$, and 11.27 \pm 3.95 . Therefore, Based on these results and assumption of $\alpha=0.05$, and $\beta=.20$, and effect size of $10 \%$ because of the probability of samples attrition, the sample size calculated as 140 people using the following formula.

$$
\mathrm{N}=\frac{\left(Z_{1} \frac{\alpha}{2}+Z_{1}-\beta\right)^{2}\left(\delta_{1}^{2}+\delta_{2}^{2}\right.}{\left(\mu_{1}-\mu_{2}\right)^{2}}
$$

The study was conducted in Gilan-e Gharb city in Kermanshah province; located in the west part of Iran. All stages of the research, conducted in the period April to December 2016. Inclusion criteria were: aged between 18 to 50 years, living in Gilan-e Gharb, having at least primary education, lack of breast diseases, and informed consent to participate in research. Exclusion criteria also included: diagnosis of breast diseases in women during the study, migration or death, as well as lack of consent to the continuation of voluntary participation in the research. The samples recruited from the public population. At the beginning of the study, the participants were randomly divided into two groups intervention and control group - each included 70 women. It should be noted that sample when doing post-test reduced to 134 people because four women in intervention group and two in control group excluded from the study. To select the samples, firstly a list of women aged 18 - 50 years who had a health dossier in healthy center of Gilan-e Gharb city was prepared. Then using the systematic random sampling method, the number of women needed based on the determined sample size and considering the inclusion criteria was selected from the list. The data were collected two stages; before the intervention and six months after the intervention, that means follow-up period (distance between the pre-test and post-test) was six months. The women were invited to refer the health center to participate in the study. Data related to the questionnaire and breast self-examination were collected in the family health unit of the health center.

Data collection tools: In this study, data gathering tool was a 3-part questionnaire. The first part included demographic questions. The second part was five questions related to the SOC for BSE, in which people at the time of study tailored to their situation were placed in one of the stages of change, including pre-contemplation, contemplation, preparation, action and maintenance. The third part of questionnaire was related to HBM in which each structure contains six questions and had a total of 30 questions. All of questions were scored on a 5-point Likert scale ranged from one to five. The maximum point of the HBM questionnaire was 150 score. Dependent variables of the study in this questionnaire were perceived susceptibility, severity, benefits, barriers, and selfefficacy related to the BSE. The validity and reliability of the HBM questionnaire related to BSE has been confirmed in Iranian studies $(12,17)$. Validity of SOC questionnaire has been confirmed by the Content Validity Index (S-CVI) as \%96, and two-week test-retest reliability of SOC has been reported as $85 \%$ (17).

Information about the accuracy of BSE as main outcome variable was collected by a midwife through observation and a coded checklist. This illustrated checklist included ten steps. Ten scores were assigned to each step and a total score on the checklist was 100. Description of each step was provided for the examiner. Face and content validity of Checklist of BSE performing was confirmed by a panel of experts. Also the reliability of data gathering checklist in multiple measurements (by different examiners) was approved (12).

\section{Educational intervention}

Initially, participants in both intervention and control groups completed a questionnaire. After analyzing the data, people were divided into three groups according to the stage of change; first group with 34 people in pre-contemplation and contemplation stages, second group including 16 women in preparation stage, and third group with 20 women in action and maintenance stages. In educational programs, the quality and quantity of education is different for various stages of behavior change. Accordingly, in this study three sessions of theoretical education was conducted for people who were in pre-contemplation and contemplation stages. The expected outcome in the first session for people in pre-contemplation and contemplation stages was increasing in awareness and acquisition of knowledge. Also educational approaches were considered providing new information, persuasive communication, and expression of emotion. In this session the breast cancer and screening procedures especially BSE was instructed. Also educator provided an insight into the sensitivity of women to breast cancer, risk factors, severity of the disease, and its negative consequences in terms of physical, social, and familial. In addition, benefits of self-examination in early diagnosis of benign and malignant of breast were introduced. In 
the second session, participants in Preparation stage were added to educational program. The expected outcome of this session was increased decision-making power which was followed by approaches such as changing attitude and skills development. At the beginning of session, a short description related to the sensitivity of women, the severity of the disease, and the benefits of performing BSE were presented for new members. In the next part of this session using brainstorming, the obstacles of performing of BSE was discussed. In this section we were trying to minimize perceived barriers and magnified the perceived benefits in women's perspective. At the end of the second session, an educational leaflet about breast cancer, risks, and importance of BSE in early diagnosis of the cancerous lump was delivered. In the third session, after training the theoretical overview, an anatomical lecture by moulage was instructed about performing of BSE. Also educator used Flip Chart with appropriate training images and text associated with the BSE. At the end of the session, an illustrated Sticker about the steps of BSE was delivered to people to use it as a reminder. In the fourth session, we invited people of action and maintenance stages to participate in training. The expected outcome of this session was to change behavior and maintain healthy behaviors, and educational approaches were understanding skills, training self-management, and changing attitudes. In this session initially people in action and maintenance stages discussed about their experiences and the reasons for adopting healthy behaviors. Then, a midwife using an instructional video re-trained the correct method of performing BSE to the woman. The control group during this period received only routine training of the family health unit of the health center. Also, the control group with was selected with appropriate geographical distance from the intervention group to preventing the contamination bias.

\section{Ethical issues}

In the present study we met the ethical issues such as acquiring approval from the Ethics Committee of Kermanshah University of Medical Sciences, explain obscure points of study to the participants, and confidentiality of personal information by researchers. Also, written informed consent form was obtained from the participants.

\section{Statistical analysis}

Statistical analysis was performed using the SPSS software package (version 19.0; SPSS, Inc., Chicago, IL, USA) for Windows. Before the statistical analysis, Kolmogorov-Smirnov test was used to assessing the normal distribution of data. Descriptive statistics were used to determine differences of subjects' demographic features. Independent and Paired t-tests, chi-square, and Wilcoxon test were used to measure the effect of education on research variables.

\section{RESULTS}

In this study, 140 women with an average age of $32.86 \pm 6.1$ years participated and divided equally into the two intervention and control groups. Results showed that the two groups in terms of mean age, history of breast masses, history of breast cancer in relatives, and level of education had no significant differences (Table 1).

In the intervention group before implementing the educational program, $71.5 \%$ of women were in passive stages including precontemplation, contemplation and preparation, and others were in the active stage including action and maintenance stages of breast self-examination. After the educational program, the distribution changed to $44 \%$ in passive stages and $56 \%$, in active stages. The Wilcoxon test showed that the changes due to education were statistically significant. In the control group, 70 and 30 percent of women were in the passive and active stages respectively, and the comparison with the post-test using Wilcoxon did not showed a significant difference. To examine the effect of education, chisquare test showed that the difference between the two groups was statistically significant after the intervention. Further result is shown in Table 2 based on the pairwise comparison.

The mean score of perceived susceptibility, perceived severity, and self-efficacy in the intervention group significantly increased after the educational program. Also In the control group, paired t-test showed that there were significant changes in mean scores of three mentioned variables. Considering these conditions, independent t-test was used to compare mean scores of intervention and control groups, and results showed that the mean score of the intervention group was significantly higher than the control group.

Table 1. Demographic characteristics of in two group of study

\begin{tabular}{|c|c|c|c|c|c|}
\hline \multirow[b]{2}{*}{ Variables } & & $\begin{array}{l}\text { Intervention group } \\
(\mathbf{n}=\mathbf{7 0})\end{array}$ & $\begin{array}{c}\text { control group } \\
(n=70)\end{array}$ & $\begin{array}{c}\text { Total } \\
(n=140)\end{array}$ & \multirow[b]{2}{*}{ P Value } \\
\hline & & $\mathbf{N}(\%)$ & $\mathbf{N}(\%)$ & $\mathbf{N}(\%)$ & \\
\hline \multirow{2}{*}{ History of breast masses } & Yes & $3(4.29)$ & $2(2.86)$ & $5(3.57)$ & \multirow{2}{*}{0.937} \\
\hline & No & $67(95.71)$ & $68(97.14)$ & $135(96.43)$ & \\
\hline \multirow{2}{*}{ Education } & Sub-Diploma & $18(25.71)$ & $21(30.00)$ & $39(27.86)$ & \multirow[b]{2}{*}{0.106} \\
\hline & Diploma & $40(57.14)$ & $34(48.57)$ & $74(52.86)$ & \\
\hline Housing & rental & $28(40.00)$ & $25(35.71)$ & $53(37.86)$ & 0.383 \\
\hline \multirow{2}{*}{ History of cancer in relatives } & Yes & $6(8.57)$ & $7(10.00)$ & $13(9.29)$ & \multirow{2}{*}{0.950} \\
\hline & No & $64(91.43)$ & $63(90.00)$ & $127(90.71)$ & \\
\hline Mean Age (year) & & $32.49 \pm 6.4$ & $33.24 \pm 6.1$ & $32.86 \pm 6.25$ & 0.452 \\
\hline
\end{tabular}


Table 2. Participants distribution based on the stages of change in the intervention and control groups before and after intervention

Intervention group

\begin{tabular}{|c|c|c|c|c|c|}
\hline Stages of change & $\begin{array}{l}\text { Pre test } \\
N=70\end{array}$ & $\begin{array}{l}\text { Post test } \\
\mathrm{N}=66\end{array}$ & $\begin{array}{c}\text { Pre test } \\
\mathbf{N}=70\end{array}$ & $\begin{array}{l}\text { Post test } \\
\mathrm{N}=68\end{array}$ & $\begin{array}{c}\text { Between two } \\
\text { groups }\end{array}$ \\
\hline Precontemplation & $13(18.6 \%)$ & $4(6.1 \%)$ & $18(25.7 \%)$ & $13(19.1 \%)$ & \\
\hline Contemplation & $21(30.0 \%)$ & $13(19.7 \%)$ & $15(21.4 \%)$ & $18(26.8 \%)$ & \\
\hline Preparation & $16(22.9 \%)$ & $12(18.2 \%)$ & $16(22.9 \%)$ & $14(20.6 \%)$ & $P=.010$ \\
\hline Action & $4(5.7 \%)$ & $20(30.3 \%)$ & $2(2.9 \%)$ & $4(5.9 \%)$ & \\
\hline \multirow[t]{2}{*}{ Maintenance } & $16(22.9 \%)$ & $17(25.8 \%)$ & $19(27.1 \%)$ & $19(27.9 \%)$ & \\
\hline & & \multicolumn{4}{|c|}{$P=.07$} \\
\hline
\end{tabular}

Table 3. HBM constructs and accuracy of BSE in the intervention and control groups before and after intervention

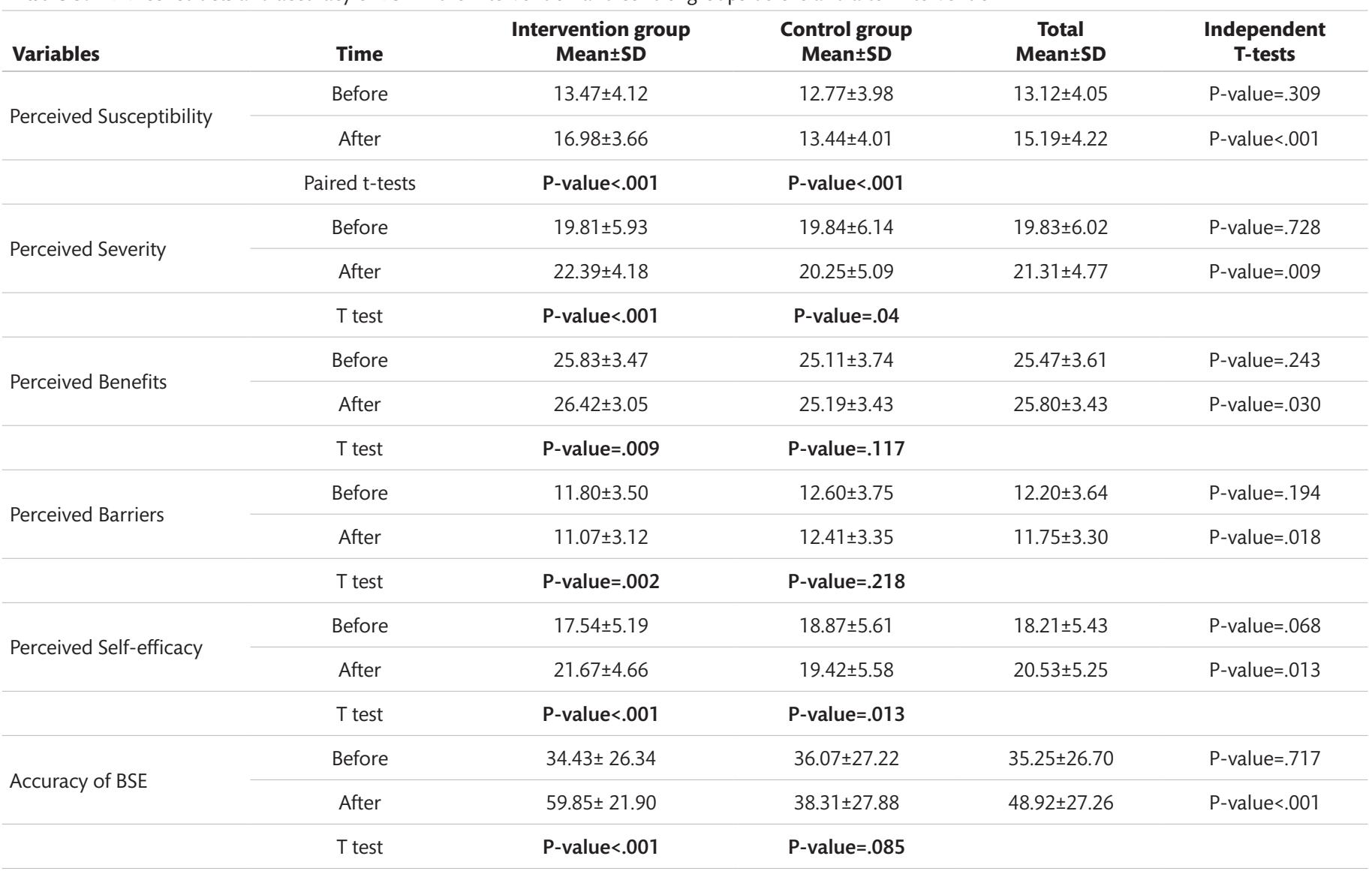

Perceived benefits after the intervention significantly increased in the intervention group but did not increased in the control group. For comparison of two intervention and control groups we used independent t-test, according to which the mean score of the intervention group was significantly higher than the control group. Perceived barriers of BSE also decreased in the intervention group after the educational program, as well as its mean score was significantly lower compared with the control group.

The accuracy of BSE was one of the main variables of the study intervention. After the intervention, mean score of BSE in the intervention group significantly increased from $34.43 \pm 26.34$ to $59.84 \pm 21.09$, while results in the control group showed no difference between the pre-test and post-test. Also independent t-test showed that the mean score of accuracy of BSE in intervention group was significantly more than the control group in the posttest. The full results of the health belief model structures as well as the accuracy of BSE showed in Table 3.

\section{DISCUSSION}

The present study aimed to promoting the breast self-examination according to which, an educational intervention was effective in promoting the active stages of breast self-examination and also changing the belief of women toward conducting the health behavior of BSE. In this study we chose the stages of change model to the assessment of BSE in participants. There are two 
types of criteria commonly used in previous studies to assess BSE, including doing or not doing the BSE, and regular or irregular BSE $(9,10,18)$. However, these measures have some limitations, most notably ignoring the readiness of individuals to behavior change in the future, and this could reduce the targeting of educational interventions.

This has been accepted that the design and implementation of programs that classify individuals on stages of change can be more effective than traditional health education interventions (19). This is a key assumption of the stage-based models that for more effectiveness of health education interventions, they must be planned on the basis of stages of change. In fact, the stagesoriented interventions are more effective than traditional actionoriented interventions because of tailoring and time specified intervention(20). This model provides a simple and effective method for classification of the target population for planning and intervention implementation. Each stage introduces separate and distinct challenges for health educators and health promoters. Therefore, health educators should recognize the importance of motivation, skills, successful experiences, and environmental and social support at various stages (21).

According to the explanations above, we used the stages of change to increase the effectiveness of program, and tailoring the content and educational activities through considering the readiness of individuals to change. In the present study by categorizing individuals according to stage of change and tailoring educational intervention, after the training program, individuals of action stage in the intervention group increased. This increase was evaluated as the positive impact of education in promoting the stages of change related to BSE.

It has been suggested that that the assessing beliefs of women in designing and implementing educational interventions for BSE will lead to promoting the intervention effects and changing behavior (22).

Perceived susceptibility is the first structure of the model, which refers to an individual's vulnerability to a particular disease or condition. In the present study, perceived susceptibility increased in intervention group. In two similar studies, educational intervention increased the sensitivity of the subjects related to the risk of breast cancer $(23,24)$. The susceptibility to a disease is very different and this depends on the perceptions and attitudes regarding the risk of disease. In this context the knowledge is a fundamental factor. The fact that poor knowledge can be dangerous refers to the perceived sensitivity (24) (21).

The second structure of HBM assessed in this study was the perceived severity. The results showed that people's perception on the severity of breast cancer promoted in the intervention group. This concept refers to the intensity, severity, and nature of disease. In the present study, we evaluated this variable by asking questions such as 5 year survival rate, threatening the marital relationship, and changing the life if people be diagnosed with cancer. Also in educational programs we demonstrated the seriousness of the problem by providing images of cancerous organs along with appropriate descriptions. There is more likelihood that person will do preventive behavior if understand further the disease severity (19). We guided women toward the active stages of behavior change including action and maintenance through awareness rising and arouse emotions in order to change attitudes particularly in the pre-contemplation, contemplation and preparation stages.

In this study, women in the both intervention and control groups had moderate perception related to the benefits of BSE. However, we pointed out the benefits of BSE in the educational programs including early detection of breast masses, raising confidence by doing it, acceptable effectiveness, and lack of side effects. One must understand that the behavior is beneficial and available in the community. Experts have noted the usefulness and feasibility as two requirements for the behavior (16). In this study, we have emphasized the usefulness of BSE in breast cancer screening, its feasibility, easily performed by a person and with minimal facilities. In other studies, education had a positive impact on increasing understanding about the benefits of $\operatorname{BSE}(23,25,26)$.

Behavior barriers refer to the characteristics of treatment and prevention that may be perceived as uncomfortable, expensive, inconvenient, painful or disturbed factors. In this study we concluded that psychological factors such as stress and worry about the finding the lumps, embarrassment, and unpleasant feeling were the most barriers to self-examination. Emphasizing these barriers, education program was conducted to resolve these barriers. Consequently, the results showed that perceived barriers in the intervention group reduced after the educational program.

Self-efficacy refers to individual's beliefs about their capabilities and the ability to organize a behavior and achieve goals (27). Previous study showed that self-efficacy after the stages of change had the highest correlation with BSE (12). Therefore, we used various methods in the intervention to improve self-efficacy of women including observing the behavior of the educator and understanding the feasibility of behavior, verbal encouragement, group support, and behavioral segmentation into smaller parts. Self-efficacy is usually higher in action and maintenance stages compared to previous stages because individuals in passive stages usually don't have a successful experience of implementation (28).

The accuracy of BSE was one of the main outcomes of this study and we conducted educational intervention to promote this behavior in the intervention group. The results showed that the behavior of BSE promoted in the intervention group. In similar studies also BSE has increased after the educational intervention based on health belief model $(17,29)$.

\section{Limitation}

One of the limitations of this study was the embarrassment of women for performing BSE, which we tried to resolve with the explanation of a family health expert. Also, since one of the data collection tools was questionnaire, there was a possibility of over- 
reporting by individuals. We therefore attempted to combine the questionnaire with observation of the practical implementation of breast self-examination to greatly reduce the likelihood of overreporting. Finally, the presence of women in training sessions was not regular, so the duration of the research was longer than the researchers had planned.

\section{CONCLUSIONS}

The results of this study indicated a positive impact of modelbased education on the behavior of breast self-examination. We used the health belief model because of its special attention to the perceptions and beliefs of the target group about adopting healthy behaviors. In addition, to enhance the tailoring of the intervention, we recruited the stages of change model to classify individuals in appropriate training groups. Finally after intervention, we concluded that educational program based on HBM and SOC can improved both active stages of BSE doing and its accuracy in the women.

\section{REFERENCES}

1. Miller KD, Siegel RL, Lin CC, et al. Cancer treatment and survivorship statistics, 2016. CA Cancer J Clin 2016;66:271-289. [CrossRef]

2. Nafissi N, Khayamzadeh M, Zeinali Z, Pazooki D, Hosseini M, Akbari ME. Epidemiology and histopathology of breast cancer in Iran versus other Middle Eastern countries. Middle East J Cancer 2018;9:243-251. http://mejc.sums.ac.ir/article_42130_ cc116542d5eaca6c302b83e5e2794604.pdf

3. Mohammadi G, Akbari ME, Mehrabi Y, Motlagh AG, Heidari M, Ghanbari S. Analysis of cancer incidence and mortality in Iran using joinpoint regression analysis. Iranian Red Crescent Med J 2017;19. [CrossRef]

4. Marzouni HZ, Lavasani Z, Shalilian M, et al. Women's awareness and attitude toward breast self-examination in Dezful city, Iran, 2013. Iranian Red Crescent Med J 2015;17. [CrossRef]

5. Gür K, Kadıoğlu H, Sezer A. Breast cancer risks and effectiveness of BSE training among women living in a district of Istanbul. J Breast Health 2014;10:154. [CrossRef]

6. Wilke LG, Broadwater G, Rabiner S, et al. Breast self-examination: defining a cohort still in need. Am J Surg 2009;198:575-579. [CrossRef]

7. Kissal A, Kartal B, Cetin O. The Determination of Knowledge, Applications and Health Beliefs of Third-and Fourth-Grade Nursing Students Regarding Breast Self-Exam. EurJ Breast Health 2017;13:1016. [CrossRef]

8. Naghibi A, Shojaeezade D, Montazeri A, Yazdani J. Early detection of breast cancer among women in Mazandaran, Iran J Health Sci 2013;1:44-49. [CrossRef]

9. Akhtari-Zavare M, Ghanbari-Baghestan A, Latiff LA, Matinnia N, Hoseini M. Knowledge of breast cancer and breast self-examination practice among Iranian women in Hamedan, Iran. Asian Pac J Cancer Prev 2014;15:6531-6534. [CrossRef]

10. Rezabeigi-davarani E, Khanjani N, Falahi M, Daneshi S, Iranpour A. Breast self-examination and its effective factors based on the theory of planned behavior among women in Kerman, Iran.J Educ Commun Health 2016;3:1-8. [CrossRef]
Informed Consent: Written informed consent form was obtained from the participants.

Compliance with Ethical Standards: This study received ethics approval from the Research Ethics Committee of Kermanshah University of Medical Sciences (2015/91148).

Peer-review: Externally peer-reviewed.

Author Contributions: Concept - HA, MK; Design - HA, MK; Supervision - HA; Fundings - HA; Materials - MK; Data Collection and/or Processing - SS, AZ; Analysis and/or Interpretation - HA, MK; Literature Search - HA, MK, SS, AZ; Writing Manuscript - HA, MK, SS, AZ; Critical Review - HA, MK, SS, AZ

Conflict of Interest: No conflict of interest was declared by the authors.

Financial Disclosure: The authors would like to thank the Kermanshah University of Medical Sciences for providing financial support for this project. (Grant Number 91148)

11. Paknejad H, Saeedi V. Knowledge, Attitudes and Practice of Breast Self-Examination among over 20 year females in Tehran, Iran. RJMS. 2019; 25:34-41.

12. Ashtarian $H$, Rohani-Rasaf M, Afshari A, et al. Stages of changes, breast self-examination practice and related beliefs in women - A theory based study. J Evolution Med Dent Sci 2018;7:3430-3435. [CrossRef]

13. Moussa M, Shalaby NS. Effect of breast self-examination education program on knowledge, attitude, and practice of nursing students. Int J Res Stud Biosci (IJRSB) 2014;2:40-49. https://www.arcjournals.org/ pdfs/ijrsb/v2-i6/7.pdf

14. Parsa P, Mirmohammadi A, Khodakarami B, Roshanaiee G, Soltani F. Effectsofbreastself-examinationconsultationbased on thehealthbelief model on knowledge and performance of Iranian women aged over 40 years. Asian Pac J Cancer Prev 2016;17:3849-3854. http://journal. waocp.org/article_33065_1069ebb631f066cb2b57f6318809a4cc.pdf

15. Masoudiyekta L, Dashtbozorgi B, Gheibizadeh M, Malehi AS, Moradi M. Applying the health belief model in predicting breast cancer screening behavior of women. Jundishapur J Chronic Dis Care 2015;4. [CrossRef]

16. Schiavo R. Health communication: From theory to practice, 2nd ed. John Wiley \& Sons; 2013.

17. Karimy M, Hasani M, Khoram R, Ghaffari M, Niknami S. The effect of education, based on health belief model on breast self-examination in health liaisons of Zarandieh city. Zahedan J Res Med Sci 2008;10.

18. Abolfotouh MA, Ala'a AB, Mahfouz AA, Al-Assiri MH, Al-Juhani $A F$, Alaskar AS. Using the health belief model to predict breast self examination among Saudi women. BMC Public Health 2015;15:1163. [CrossRef]

19. DiClemente RJ, Crosby RA, Kegler MC- editors. Emerging theories in health promotion practice and research: Strategies for improving public health. San Francisco, CA: John Wiley \& Sons; 2002.

20. Bamberg S. Applying the stage model of self-regulated behavioral change in a car use reduction intervention. J Environ Psychol 2013;33:68-75. [CrossRef]

21. Butler JT. Principles of health education and health promotion. Englewood, Colo.: Morton Publishing Company; 1994. 
22. Shams M, Fayazbakhsh A, Safari M. A Review of Studies Conducted on Efficacy of Health Educational Interventions to Correct Women's Behavior in Performing Breast Self-examination. Basic Clin Cancer Res 2014;6:2-9.

23. Secginli $S, N a h c i v a n$ NO. The effectiveness of a nurse-delivered breast health promotion program on breast cancer screening behaviours in non-adherent Turkish women: A randomized controlled trial. Int J Nurs Stud 2011;48:24-36. [CrossRef]

24. Hacıhasanoğlu R, Gözüm S. The effect of training on the knowledge levels and beliefs regarding breast self-examination on women attending a public education centre. Eur J Oncol Nurs 2008;12:58-64. [CrossRef]

25. Mohamed HAE-A, Ibrahim YM, Lamadah SM, Hassan M, El-Magd A. Application of the health belief model for breast cancer screening and implementation of breast self-examination educational program for female students of selected Med and non-Med faculties at Umm al Qura University. Life Sci J 2016;13:21-33. http://www.lifesciencesite. com/lsj/life130516/03_30418Isj130516_21_33.pdf
26. Aghamolaei T, Hasani L, Tavafian SS, Zare S. Improving Breast SelfExamination: an Educational Intervention Based on Health Belief Model. Iranian J Cancer Manag 2011;4:e80735.

27. Bandura A. Self-efficacy: The exercise of control. W H Freeman/Times Books/ Henry Holt \& Co.; 1997.

28. Parhoodeh $Y$, Khezeli M, Bakhtiyari M, Delpisheh A, Latifi A. Effect of education based on Trans-theoretical model on physical activity behavior in college students. J Health Sys Res 2012;8:320-329.

29. Khiyali Z, Aliyan F, Kashfi SH, Mansourian M, Jeihooni AK. Educational intervention on breast self-examination behavior in women referred to health centers: application of health belief model. Asian Pac J Cancer Prev 2017;18:2833-2838. [CrossRef] 